\title{
Storage Temperature Affects Viability of Banksia menziesii Pollen
}

\author{
Tina L. Maguire and Margaret Sedgley ${ }^{1}$ \\ Department of Horticulture, Viticulture and Oenology, University of Adelaide, \\ Waite Campus, Plant Research Centre, PMB 1 Glen Osmond, SA 5064, \\ Australia
}

Additional index words. Banksia menziesii, Proteaceae, pollen viability, pollen storage, in vitro germination

\begin{abstract}
Storage of Banksia menziesii pollen was assessed at $20,4,-20,-80$, and $-196{ }^{\circ} \mathrm{C}$ using a semisolid medium of $1 \%$ agar, $15 \%$ sucrose, $0.01 \%$ boric acid, $0.03 \%$ calcium nitrate, $0.02 \%$ magnesium sulfate, $0.01 \%$ potassium nitrate, and an incubation temperature of $25{ }^{\circ} \mathrm{C}$. The germination percentage remained constant at $\approx 70 \%$ in all treatments except for pollen stored at $20^{\circ} \mathrm{C}$, which exhibited only $25 \%$ germination after 6 months. Pollen viability was assessed using fluorescein diacetate (FDA), but the results did not reflect the loss of germinability at $20^{\circ} \mathrm{C}$ and correlation with in vitro results was variable. Floret position on the inflorescence did not affect germination, but pollen viability varied over the flowering period with maximum germination at midseason.
\end{abstract}

Pollen storage is an important component of plant breeding programs when the species or individuals to be hybridized do not flower at the same time, or are geographically isolated. Banksia species (Proteaceae) are cultivated in Australia, Israel, and the United States for cut flowers, and recent work on the development of crossing techniques has stimulated the use of interspecific hybridization in Banksia breeding (Fuss and Sedgley, 1991; Sedgley et al., 1994). Flexibility of the breeding program would be greatly increased if pollen viability could be maintained in storage. Ramsey and Vaughton (1991) used fluorescein diacetate (FDA) and acetocarmine to assess the viability of fresh $B$. menziesii pollen, but to our knowledge no published information is known on pollen collection and storage, or on in vitro conditions for successful pollen germination and tube growth.

Storage conditions vary for plant species, and in most woody species low humidity and low temperature are optimal (Akihama and Omura, 1986; Stanley and Linskens, 1974). Dehydration of pollen to $3 \%$ to $5 \%$ moisture increases pollen longevity at low temperature, but the pollen must be rehydrated before it will germinate (Yates and Sparks, 1989). Pollen viability testing methods include staining tests and in vitro pollen germination (Sedgley and Griffin, 1989). Staining methods such as FDA rely on the activity of pollen enzymes, which

Received for publication 2 Dec. 1996. Accepted for publication 14 Feb. 1997. We thank the Australian Research Council for funding, S.A. Water and Phil Howlett for access to Banksia collections, and Rita Middelberg for assistance with statistical analysis. T.L. Maguire is the recipient of an Australian Postgraduate Research Award. The cost of publishing this paper was defrayed in part by the payment of page charges. Under postal regulations, this paper therefore must be hereby marked advertisement solely to indicate this fact.

${ }^{1}$ To whom reprint requests should be addressed. may persist after the ability of the pollen grain to effect seed set has declined. Similarly, in vitro pollen germination does not always reflect true viability, and lack of reproducibility of results has been demonstrated in some genera including Acacia (Sedgley and Harbard, 1993). The ability of pollen to effect seed set is the most accurate test of viability, but time constraints dictate that indirect methods are widely used. The objectives of this study were to develop pollen viability testing methods for Banksia and practical methods for long-term storage.

\section{Materials and Methods}

Plant material. Plants of $B$. menziesii were located in collections at Happy Valley (lat. $35^{\circ} 04^{\prime} \mathrm{S}$, long. $138^{\circ} 34^{\prime} \mathrm{E}$ ) and Nangkita (lat. $35^{\circ} 20^{\prime} \mathrm{S}$, long. $138^{\circ} 36^{\prime} \mathrm{E}$ ), South Australia. Both sites have a mediterranean climate with winter rainfall. The mean maximum and minimum temperatures $\left({ }^{\circ} \mathrm{C}\right)$ during the experimental period (June-August) were $15.80 \pm 1.02$ and $8.03 \pm 0.48$ at Happy Valley, and 16.33 \pm 0.95 and $9.16 \pm 0.32$ at Nangkita. Mean total rainfall $(\mathrm{mm})$ during the experimental period was $86.73 \pm 38.54$ at Happy Valley and 129.20 \pm 65.35 at Nangkita. The soils comprised sand or loamy sand with a loose grain structure. All experimental plants were grown from seed, and ranged in age from 3 to 15 years. Experiments were conducted over the flowering season of B. menziesii from June to August over 3 years.

Pollen collection. Banksia menziesii inflorescences comprise hundreds of florets, and in preliminary experiments pollen was collected from the upper, middle, and lower thirds of four inflorescences from the same plant. Pollen was also collected from the middle third of three inflorescences from three plants at monthly intervals during the flowering period. In subsequent experiments, pollen was collected in the middle of the season from the middle third of three inflorescences from each of three plants. Pollen from all inflorescences of each plant were mixed together to give a pooled sample.

Pollen storage. Florets with dehisced anthers were removed and placed in $1.5-\mathrm{mL}$ eppendorf tubes in a desiccator over silica gel (pre-equilibrated for 1 month) for $24 \mathrm{~h}$ at $4{ }^{\circ} \mathrm{C}$. They were placed in containers with silica gel at $20,4,-20,-80$, or $-196^{\circ} \mathrm{C}$ (liquid N). Pollen was stored for up to 6 months and tested following a period of rehydration at $100 \%$ humidity for $1 \mathrm{~h}$. Killed pollen, which was kept at $60^{\circ} \mathrm{C}$ for $5 \mathrm{~d}$, was used as a control.

In vitro germination. The basal semisolid medium comprised $1 \%$ agar, $0.01 \%$ boric acid, $0.03 \%$ calcium nitrate, $0.02 \%$ magnesium sulfate, and $0.01 \%$ potassium nitrate in $7-\mathrm{cm}$ diameter petri dishes (Stanley and Linskens, 1974). Three sugar sources, sucrose, lactose, and fructose, were tested at a concentration of $10 \%$. The best sugar source was tested at $5 \%$, $10 \%, 15 \%$, and $20 \%$. Incubation temperatures tested for the best medium were $15,20,25,30$, and $35^{\circ} \mathrm{C}$. Pollen germination was scored using a dissecting microscope after incubation for $18 \mathrm{~h}$ on the medium. At least 250 randomly selected pollen grains in different fields of view were scored for germination; the criteron for pollen germination was a tube length that exceeded the grain diameter. Pollen tube length was measured for 10 grains.

Fluorescein diacetate (FDA) test. Pollen was placed on a slide with two drops of FDA (Heslop-Harrison et al., 1984). An interval of 30 min allowed penetration of the FDA into the pollen grain before observation with a fluorescence microscope. At least 250 grains were counted in different areas of the slide, and scored for the presence of fluorescing and nonfluorescing grains. Grains that were bright and consistent in fluorescence were scored as viable, and those that were nonfluorescing, or had weak and patchy fluorescence, as inviable.

Statistical analysis. All experiments were randomized complete-block designs, using plants as blocks with three replicates per treatment. Results were analyzed using analysis of variance with the statistical package Genstat 5 (Payne, 1987). Correlation coefficients $(r)$ and coefficients of determination $\left(r^{2}\right)$ were calculated by plotting a line of best fit.

\section{Results}

In vitro germination. Sugar source affected $(P<0.05)$ germination of pollen collected from the middle third of the inflorescence in midflowering season, but not pollen tube length. Sucrose gave the highest percentage of germination $(61.4 \%)$, with glucose $(20.3 \%)$ and lactose $(12.0 \%)$ supporting poor germination. Sucrose concentration affected both pollen germination $(P<0.01)$ and pollen tube length $(P<0.001)$. There was no significant difference between $10 \%, 15 \%$, and $20 \%$ sucrose in percentage of pollen germination $(50.6 \%$, $68.9 \%, 60.1 \%$, respectively), or tube length $(96.3,100.0,121.3 \mu \mathrm{m}$, respectively), but responses were lower with $5 \%$ sucrose $(18.1 \%$, 
$67.5 \mu \mathrm{m})$. A concentration of $15 \%$ sucrose was used in further experiments. Temperature affected both pollen germination percentage $(P$ $<0.001)$ and pollen tube length $(P<0.05)$. Pollen germination was highest at 15 to $25^{\circ} \mathrm{C}$, with no significant differences among these temperatures $(57.9 \%, 56.4 \%, 57.0 \%$, respectively). Germination declined at $30^{\circ} \mathrm{C}(13.6 \%)$ and was almost nil at $35^{\circ} \mathrm{C}(0.5 \%)$. Pollen tubes were longest at 15 to $25^{\circ} \mathrm{C}(137.5$, $116.3,100.0 \mu \mathrm{m}$, respectively), with reductions at $30^{\circ} \mathrm{C}(77.5 \mu \mathrm{m})$ and at $35^{\circ} \mathrm{C}(28.8$ $\mu \mathrm{m})$. An incubation temperature of $25^{\circ} \mathrm{C}$ was used in further experiments.

Effect of position on the inflorescence and time during the flowering season. In vitro tests showed no significant effect of position on the inflorescence on germination percentage or on pollen tube length (Table 1). Time of season significantly affected FDA staining and pollen germination, with pollen collected at the start of the season showing lower viability than at mid- and late season (Table 1). The correlation between FDA staining and in vitro germination was high $\left(r^{2}=0.8\right)$.

Pollen storage. Effects of storage temperature, time, and their interaction on pollen germination were all significant. Germinability was retained in all treatments except $20^{\circ} \mathrm{C}$. Storage temperature did not affect pollen tube length significantly, although time in storage did. Pollen viability, as measured by FDA staining, was not affected by temperature, but the effect of storage time was significant (Table 2). Coefficients of determination $\left(r^{2}\right)$ for percentage of germination in vitro vs. FDA staining results were $0.536,0.902,0.875,0.462$, and 0.805 for pollen stored for 6 months at 20 , $4,-20,-80$, and $-196^{\circ} \mathrm{C}$, respectively. Killed pollen did not germinate and FDA staining indicated $3 \%$ viability.

\section{Discussion}

Our results indicate that Banksia pollen, after drying and storage over silica gel, can be stored relatively cheaply in a refrigerator or freezer long enough for breeding requirements. Storage above $0{ }^{\circ} \mathrm{C}$ is not feasible for more than a few weeks. Extended pollen storage reduces the length of the pollen tubes obtained in vitro and this may influence the ability of pollen to effect fertilization.

In vitro germination of $B$. menziesii pollen was not significantly affected at temperatures from 15 to $25^{\circ} \mathrm{C}$, perhaps reflecting natural conditions in the field environment during the flowering season. Pollen of the species $B$. coccine $a$ and $B$. integrifolia was also tested, and germinated well on the in vitro medium.

Table 1. Effects of position on the inflorescence and time of collection during the flowering season on viability of pollen of $B$. menziesii.

\begin{tabular}{lccc}
\hline \hline Variable & Germination (\%) & Tube length $(\mu \mathrm{m})$ & Fluorescence $(\%)$ \\
\hline & & Position & on inflorescence \\
Upper third & 72.2 & 88.8 & $-z$ \\
Middle third & 77.6 & 91.3 & - \\
Lower third & 71.8 & 96.3 & - \\
Probability & $\mathrm{NS}$ & NS & \\
& & Time during season & \\
June & 63.4 & 115.0 & 52.2 \\
July & 75.8 & 96.3 & 82.9 \\
August & 70.2 & 90.0 & 83.1 \\
Probability & $<0.001$ & $<0.05$ & $<0.001$ \\
\hline 'Not tested & & &
\end{tabular}

Table 2. Effects of storage temperature and time on viability of pollen of B. menziesii.

\begin{tabular}{|c|c|c|c|c|}
\hline $\begin{array}{l}\text { Storage } \\
\text { temp }\left({ }^{\circ} \mathrm{C}\right)\end{array}$ & $\begin{array}{c}\text { Time } \\
\text { (months) }\end{array}$ & $\begin{array}{c}\text { Germination } \\
(\%)\end{array}$ & $\begin{array}{l}\text { Tube length } \\
(\mu \mathrm{m})\end{array}$ & $\begin{array}{c}\text { Fluorescence } \\
(\%)\end{array}$ \\
\hline \multirow[t]{3}{*}{$\overline{20}$} & 0 & 84.6 & 100.0 & 85.4 \\
\hline & 3 & 53.1 & 87.5 & 62.0 \\
\hline & 6 & 26.3 & 63.8 & 59.7 \\
\hline \multirow[t]{3}{*}{4} & 0 & 84.6 & 100.0 & 85.2 \\
\hline & 3 & 72.1 & 85.0 & 70.0 \\
\hline & 6 & 65.2 & 63.8 & 66.2 \\
\hline \multirow[t]{3}{*}{-20} & 0 & 84.6 & 100.0 & 85.4 \\
\hline & 3 & 71.3 & 90.0 & 74.1 \\
\hline & 6 & 72.6 & 73.8 & 65.5 \\
\hline \multirow[t]{3}{*}{-80} & 0 & 84.6 & 100.0 & 85.4 \\
\hline & 3 & 66.6 & 92.5 & 53.8 \\
\hline & 6 & 68.5 & 77.5 & 53.6 \\
\hline \multirow[t]{3}{*}{-196} & 0 & 84.6 & 100.0 & 85.4 \\
\hline & 3 & 67.6 & 90.0 & 58.0 \\
\hline & 6 & 72.7 & 76.3 & 67.9 \\
\hline \multicolumn{5}{|l|}{ Probability } \\
\hline Temperature & $<0.001$ & NS & NS & \\
\hline Time & $<0.001$ & $<0.001$ & $<0.001$ & \\
\hline Interaction & $<0.05$ & NS & NS & \\
\hline
\end{tabular}

The FDA test appeared to be less reliable than in vitro germination. In particular, the pollen stored at $20^{\circ} \mathrm{C}$ fluoresced well, but had low in vitro germinability. Correlations between the germination and FDA results were good in some cases and poor in others, indicating differences in sensitivity between the two techniques. Poor correlation between FDA tests and in vitro germination has been reported in Elocharis, Lonicera (Shivanna and HeslopHarrison, 1981), and Acacia (Sedgley and Harbard, 1993). FDA tests two properties of the pollen grain, the integrity of the plasmalemma of the vegetative cell and the presence of esterase capable of cleaving the fluorogenic esterfluorescein diacetate (HeslopHarrison et al., 1984). Thus, FDA tends to overestimate the germinability of the pollen. It is, however, more accurate than other forms of viability testing, such as lactophenol, fuschin, acetocarmine, and benzidine, as tested on Solanum pollen (Heslop-Harrison and HeslopHarrison, 1970). Floret position on the inflorescence had no significant effect on pollen viability, so pollen can be collected from any part of the inflorescence, as long as the pollen is fresh. The optimal time for pollen collection was mid- to late season.

\section{Literature Cited}

Akihama, T. and M. Omura. 1986. Preservation of fruit tree pollen. Biotechnol. Agr. For. 1:101112.

Fuss, A.M. and M. Sedgley. 1991. The development of hybridisation techniques for Banksia menziesii for cut flower production. J. Hort. Sci. 66:357365.

Heslop-Harrison, J. and Y. Heslop-Harrison. 1970. Evaluation of pollen viability by enzymatically induced fluorescence: Intracellular hydrolysis of fluorescein diacetate. Stain. Technol.45:115120.

Heslop-Harrison, J., Y. Heslop-Harrison, and K.R. Shivanna. 1984. The evaluation of pollen quality, and a further appraisal of the fluorochromatic (FCR) test procedure. Theor. Appl. Genet. 67:367-375.

Payne, C.D. 1987. Genstat 5 reference manual. Oxford Univ. Press, Oxford.

Ramsey, M. and G. Vaughton. 1991. Self-incompatibility, protandry, pollen production and pollen longevity in Banksia menziesii. Austral. J. Bot. 39:497-504.

Sedgley, M. and A.R. Griffin. 1989. Sexual reproduction of tree crops. Academic, London.

Sedgley, M. and J. Harbard. 1993. Pollen storage and breeding system in relation to controlled pollination of four species of Acacia (Leguminosae: Mimosoideae). Austral. J. Bot. 41:601-609.

Sedgley, M., M.G. Sierp, and T.L. Maguire. 1994. Interspecific hybridisation involving Banksia prionotes Lind. and Banksia menziesii $\mathrm{R} . \mathrm{Br}$. (Proteaceae). Intern. J. Plant Sci. 155:755-762.

Shivanna, K.R. and J. Heslop-Harrison. 1981. Membrane state and pollen viability. Ann. Bot. 47:759-770.

Stanley, R.G. and H.F. Linskens. 1974. Pollen: Biology, biochemistry and management. Springer-Verlag, New York.

Yates, I.E. and D. Sparks. 1989. Hydration and temperature influence in vitro germination of pecan pollen. J. Amer. Soc. Hort. Sci. 114:599605. 